\title{
A simplified damage evolution relationship and deformation characteristics of a pozzolanic lime mortar when subjected to unloading-reloading cycles in the pre-peak region
}

\author{
Kostas Kaklis \\ School of Mineral Resources Engineering, Technical University of Crete, Chania 73100, Greece \\ kaklis@mred.tuc.gr, https://orcid.org/0000-0003-2722-5915 \\ Zach Agioutantis \\ Department of Mining Engineering, University of Kentucky, Lexington, Kentucky 40506, USA \\ zach.agioutantis@uky.edu, bttps://orcid.org/0000-0002-9799-4114 \\ Stelios Mavrigiannakis \\ School of Mineral Resources Engineering, Technical University of Crete, Chania 73100, Greece \\ smaurig@mred.tuc.gr, bttps:/ / orcid.org/0000-0002-6409-6043 \\ Pagona Maravelaki-Kalaitzaki \\ School of Architectural Engineering, Technical University of Crete, Chania 73100, Greece \\ nmaravel@elci.tuc.gr, bttps:/ /orcid.org/0000-0002-8776-6695
}

\begin{abstract}
Two series of uniaxial and triaxial compression tests including unloading-reloading cycles were performed under different confining pressures, in order to study the stress-strain and the deformation behavior of a pozzolanic lime mortar subjected to cyclic loading. Each test included a cyclic loading sequence using five loops in the pre-peak region. The experimental results showed that the specimens exhibit a strain-softening behavior for uniaxial and low pressure triaxial tests and a strain-hardening behavior for higher triaxial compression tests. The mortar specimens subjected to triaxial compressive cyclic loading at higher confining pressures failed along a single or conjugate shear planes accompanied by considerable lateral expansion. The marked Young's modulus degradation behavior in the prepeak region is related to damage that occurs in each specimen.
\end{abstract}

KEYWORDS. Pozzolanic lime mortar; Cyclic loading; Plastic strain; Young's modulus degradation; Damage evolution.

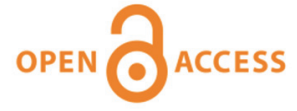

Citation: Kaklis K., Agioutantis Z., Mavrigiannakis S., Maravelaki-Kalaitzaki P., A simplified damage evolution relationship and deformation characteristics of a pozzolanic lime mortar when subjected to unloading-reloading cycles in the pre-peak region, Frattura ed Integrità Strutturale, 50 (2019) 395-406.

Received: 22.01 .2019

Accepted: 25.05.2019

Published: 01.10.2019

Copyright: (C) 2019 This is an open access article under the terms of the CC-BY 4.0, which permits unrestricted use, distribution, and reproduction in any medium, provided the original author and source are credited.

\section{INTRODUCTION}

$\mathrm{T}$ he authors have previously investigated and published the mechanical properties of a pozzolanic lime mortar, which consists of carbonate sand, hydrated lime and metakaolin (ML) [1]. Pozzolanic mortars have multiple appli- 
cations in the restoration of ancient monuments or historic structures. This particular mortar is often used as a filler or joint material in restoration projects [2,3], subjected to shear stresses that may develop along the mortar-stone interface. Stone blocks in ancient monuments were typically joined together using metallic connectors in order to provide structural integrity in case of dynamic loading. More specifically, the structural elements of the monuments on the Acropolis of Athens were initially joined together using "I"-shaped metallic connectors placed in appropriate grooves which were filled with molten lead [4]. The restoration process of the Parthenon in Athens, Greece involved the replacement of a number of marble epistyles [5] where titanium connectors were placed in carved grooves which were then filled with a cement based mortar. Titanium prohibits the use of lead as the "titanium-lead" bimetallic contact forms a strong galvanic element [4]. Pozzolanic mortars can also be used as filler material when seating metallic connectors in grooves carved into the original or restored stone fragments. Apart from this explicit use as filling material, pozzolanic mortars used as rubble, joint, finishing and capping mortars can provide particular durability to the masonry with respect to both external loading and weathering. The longevity of some ancient structures, such as the Pantheon, the Colosseum, Hagia Sofia, etc., can also be attributed to the use of pozzolanic mortars as the main joint material. Therefore, pozzolanic mortars and especially the lime-metakaolin system studied in this research, are very important in the conservation field and particularly when repair mortars are intended to be integrated in ancient structures.

This work aims to provide evidence that pozzolanic lime mortars can replace cement-based mortars in historic structure restoration projects, thus mitigating potential problems arising from salt-induced decay and material incompatibility in physico-chemical and mechanical terms, which are typically attributed to the cementitious component of cementbased mortars.

Although mortars are typically characterized by their elastic properties and material strength values, it is very important to also include their inelastic or plastic characteristics as the latter are often responsible for their successful longterm performance.

Deformations and resulting damage of materials such as concrete and mortars typically follow the elastic-plastic damage model. The elastic-damage and elastic-plastic models differ in that the elastic-plastic models can simultaneously take into account the accumulation effect of plastic strains and elastic modulus degradation [6]. In order to investigate the deformation characteristics and damage evolution with respect to rocks and concrete, it is necessary to perform a series of experiments. Many uniaxial and triaxial experiments under a loading-unloading-reloading regime (cyclic loading) have been conducted and are reported in the international literature (e.g., test on rocks $[7,8]$ and concrete $[9,10])$. The authors have also performed such tests on mortars $[1,11]$ and have shown that such specimens predominantly exhibit a plastic behavior. Some of these experiments [11] were focused on examining the stress-strain behavior and deformation characteristics of a pozzolanic lime mortar in the pre-peak region of the stress-strain curve. The term "cyclic loading" refers to the loading-unloading-reloading procedure which was utilized to gain a better understanding of the elasto-plastic properties of the material. Details on this test are given by Gatelier et al. [7]. This investigation further analyzes the results from two series of uniaxial and triaxial compression tests under cyclic loading, which were recently completed by the authors [11]. Future work will aim at experimentally investigating the post-peak region behavior of the material in order to suggest a complete damage evolution law.

\section{MATERIAL AND METHODS}

\section{Composition of the poz:olanic mortar}

he properties and constitution of the pozzolanic mortar used in the experiments previously conducted by the authors are described in detail in [11]. In summary, a mix design of sand, lime and metakaolin (at 50, 30 and $20 \% \mathrm{w} / \mathrm{w}$, respectively) was developed utilizing a water to binder ratio of 0.92 . Mixing took place at ambient conditions. The specific weight ratio of hydrated lime and metakaolin of 1.5 used, ensured that a fully developed pozzolanic reaction of the metakaolin with hydrated lime could occur. Eventually, any unreacted proportion of the hydrated lime is considered to contribute to the plasticity of the final mortar after its carbonation [12]. Through this process the mortar is assumed to acquire a pore size distribution similar or compatible to porous stone, thus facilitating the homogeneous distribution of water and more importantly allowing the water vapor to escape through the composite system $[2,3]$.

Additionally, in an effort to improve the performance characteristics of the mortar, the sand used in the mix consisted of equal proportions of carbonate sand passing through the 125 and $63 \mu \mathrm{m}$ sieves.

\section{Preparation of specimens for mechanical experiments}

The preparation of specimens has been described in detail in [11]. Previous research by the authors [1] indicated that it is better to develop cylindrical mortar specimens by coring mortar blocks compared to direct casting into cylinders. Mortar specimens were cast in prismatic molds constructed out of wooden particle boards. The mold was removed two days after casting and the mortar was allowed to cure in a curing chamber at a relative humidity (RH) of 90-95\% 
and a temperature (T) of $20^{\circ} \mathrm{C}$ with respect to the EN 196-1 standard. Specimens were allowed to cure for 26 days in the curing chamber and followed by two days in ambient conditions prior to testing as outlined in the methodology described by Gameiro et al. [13]. Cored cylinders were then cut and ground to provide smooth loading surfaces for both the uniaxial and triaxial tests following the recommendations for rock mechanics tests $[14,15]$. The diameter of the mortar cylinders was $50 \mathrm{~mm}( \pm 2 \mathrm{~mm})$ and their height was $100 \mathrm{~mm}( \pm 3 \mathrm{~mm})$ thus ensuring a height to diameter ratio $(\mathrm{h} / \mathrm{D})$ approximately equal to 2 .

\section{EXPERIMENTAL SETUP}

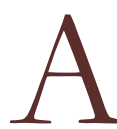

series of uniaxial and triaxial compression tests were performed on mortar specimens using a stiff $1600 \mathrm{kN}$ MTS hydraulic testing frame (model 815) which could apply the axial load either through load-control or displacement-control. The tests were used to obtain the stress-strain behavior and the deformation characteristics of the pozzolanic lime mortar specimens under cyclic (loading-unloading and reloading) conditions. As mentioned in previous studies [1,11], this particular pozzolanic mortar has been considered as an isotropic material due to the finegrained materials that it contains as well as the mixing and casting procedures used. Although all of the specimens were considered equivalent, irrespectively of how they were oriented during preparation and testing, in the present study specimens were extracted parallel to the casting direction in order to avoid any variations in the calculated mechanical parameters of the mortar, due to the consolidation direction in the casting block. Tests were typically conducted using load control at a constant load rate during the initial loading stages and displacement (stroke) control during the final loading stage. The final loading stage starts from the bottom of the unloading curve of the last loop. Thus, apart from the pre-peak stress-strain curve and the peak stress value, the post-peak stress-strain curve was also recorded.

An external $500 \mathrm{kN}$ load cell by Maywood was inserted between the loading platen and the specimen in the uniaxial tests. Triaxial tests were conducted using a Wykeham Farrance triaxial chamber (Fig.1a) with a maximum lateral pressure capacity of $14 \mathrm{MPa}$. The triaxial cell was mounted on the testing frame and axial load was directly applied to the loading piston without an external load cell.
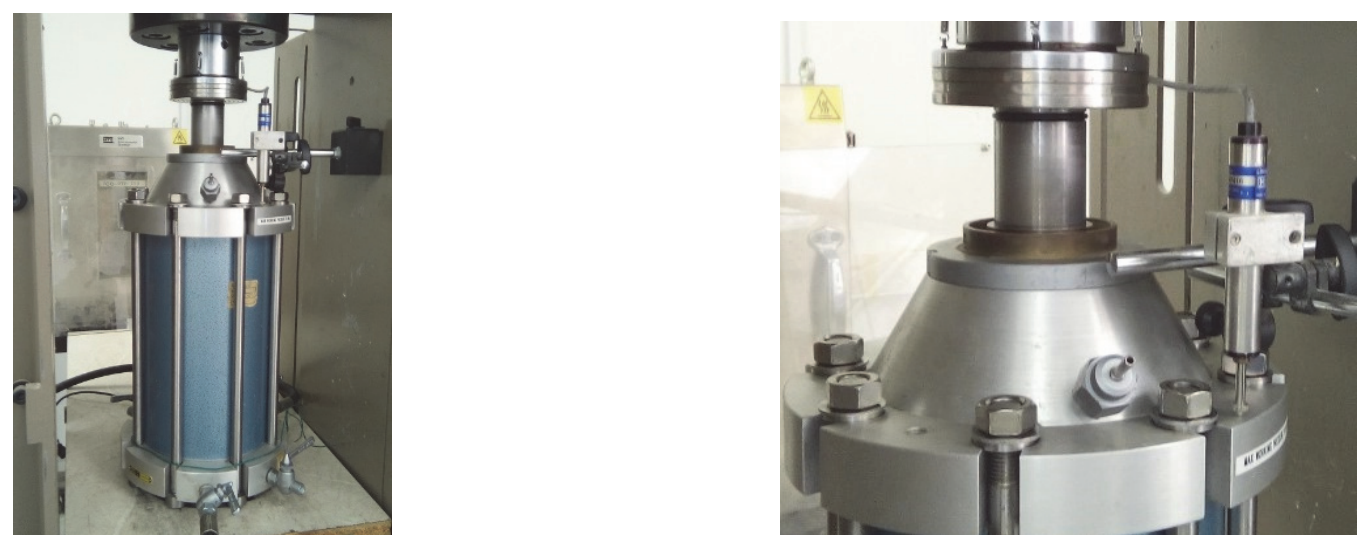

Figure 1: (Left) The triaxial chamber mounted inside the MTS 815 frame; (Right) The external LVDT experimental setup for measuring the axial deformation values during the triaxial compression cyclic tests.

The triaxial compression tests were carried out under confining pressures of 1.15, 2.09, 3.96, and 6.06 MPa. A cyclic loading sequence with five loops was used in both the uniaxial and the triaxial compression tests. The five unloadingreloading loops were performed in the pre-peak region and the axial load was applied under load control with a rate of $200 \mathrm{~N} / \mathrm{s}$. The load increment from one loop to the next ranged from 2.5 to $3.5 \mathrm{kN}$. In the final loading step the axial load was applied under displacement control with a rate of $0.01 \mathrm{~mm} / \mathrm{s}$ in order to obtain the complete stress-strain curve in the post-peak region. Axial strain was measured during the uniaxial and triaxial compression tests using the displacement sensor of the loading frame as well as an external LVDT sensor, in order to get more accurate and comparable strain measurements from these tests (Fig.1b). As the most representative and reliable strain measurements are realized using electrical strain gages, uniaxial tests were instrumented with strain gages as well. However, strain gages were not utilized in triaxial compression tests, as the triaxial chamber did not allow for that.

In cyclic loading, when a specimen is compressed up to a deviator stress level, then unloaded to zero deviator stress and then reloaded, the unloading and reloading branches are in most cases different from the initial loading curve (Fig. 2), as well from each other, forming a narrow loop that can be approximated by a straight line. The Young's modulus of the material can be derived from the slope of this line $[8,16]$.

In cyclic loading the strain is partly elastic and partly plastic. The elastic strain $\varepsilon_{e l}$ is defined as the recovered deformation by unloading to zero deviator stress, while the plastic strain $\varepsilon_{p l}$ is defined as the accumulated residual axial strain 
of the material after being unloaded to zero stress (Fig.2) [16, 17]. This plastic strain includes various types of unrecoverable deformation due to dislocation, viscous-flow and micro-fracturing [18].

In this study the Young's modulus was calculated as shown in Fig.2. This method is only based on elastic strain when compared to methods proposed by other investigators [19, 20, 21] who utilize additional deformation parameters for the calculation of Young's modulus.

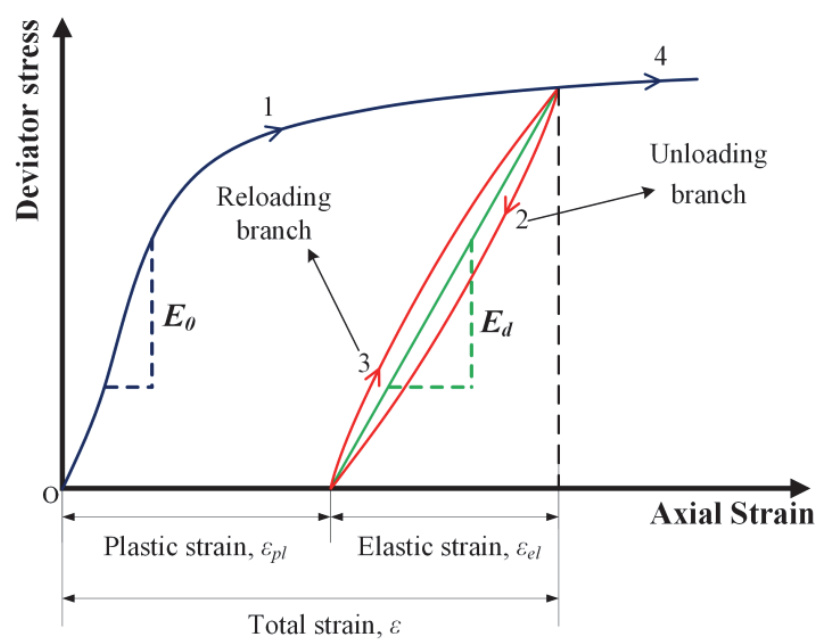

Figure 2: Typical stress-strain curve under cyclic loading.

\section{EXPERIMENTAL RESULTS AND DISCUSSION}

\section{Unloading - reloading (cyclic) stress - strain relation}

$\mathrm{F}$ ig.3a presents typical deviator stress-strain curves with five loading-unloading cycles under uniaxial compressive and conventional triaxial compressive loading for confining pressures of $1.15 \mathrm{MPa}, 2.09 \mathrm{MPa}$ and $6.06 \mathrm{MPa}$. The stress-strain responses indicated that the mortar becomes ductile even under low confining pressure. The initial part of deformation before yielding, the so-called elastic part, is significantly curved and includes appreciable permanent deformation. In addition, two different types of deformation are illustrated in Fig.3a: (a) specimens under uniaxial compression and triaxial compression at low confining pressure $(1.15 \mathrm{MPa})$ exhibited a strain-softening behavior with an easily identifiable peak stress, and (b) specimens under triaxial compression at higher confining pressures $(2.09 \mathrm{MPa}$ and $6.06 \mathrm{MPa}$ ) exhibited a strain-hardening behavior. At higher confining pressures, peak stress which corresponds to failure is not easily recognized due to the large strain on a strain-hardening curve [22].

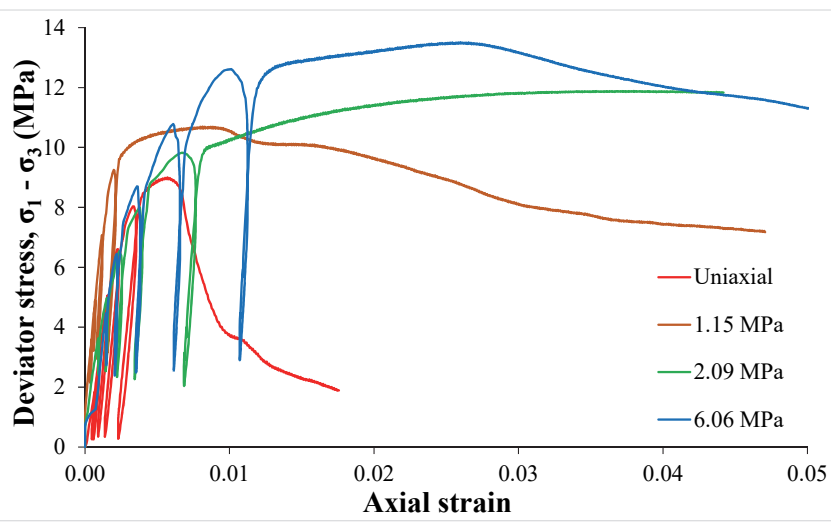

(a)

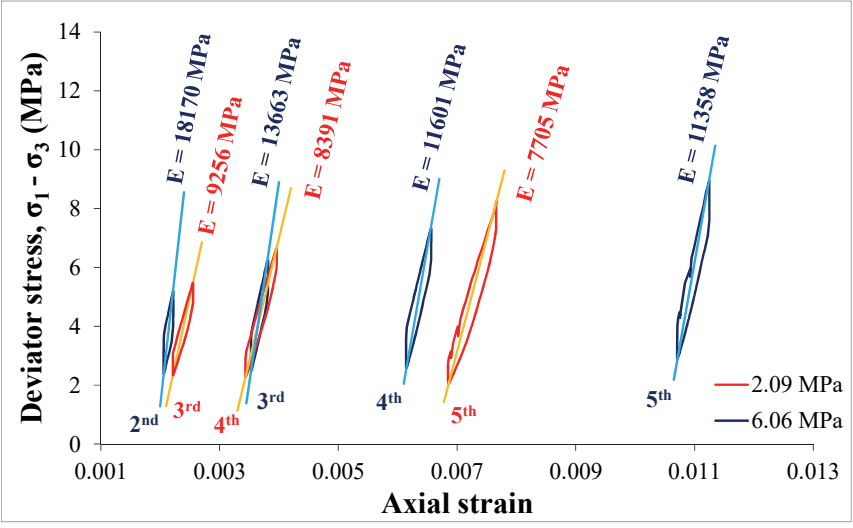

(b)

Figure 3: (a) The complete deviator stress-strain curve for pozzolanic lime mortar specimens tested in uniaxial and triaxial cyclic loading under confining pressures of 1.15 MPa, 2.09 MPa and 3.96 MPa; (b) The mean Young's modulus for each loop of the triaxial cyclic loading under confining pressures of $2.09 \mathrm{MPa}$ and $3.96 \mathrm{MPa}$.

The Young's modulus values were calculated at each cycle as discussed previously $[8,16]$ and are presented in Fig.3b for each of the four last loops in the case of triaxial compression tests under confining pressures of $2.09 \mathrm{MPa}$ and $6.06 \mathrm{MPa}$. In both cases of cyclic triaxial compressive loading, it is obvious that the Young's modulus decreases with increasing strain. 


\section{Deformation characteristics}

One uniaxial compression test and four triaxial compression tests under cyclic loading conditions were performed in order to examine the deformation characteristics of the pozzolanic lime mortar. By processing the experimental data the plastic strain, the total strain as well as the Young's modulus of the material were determined and presented in Table 1, for each one of the five loops.

Note that in the loops performed at relatively low stress levels of the triaxial cyclic compression test with lateral pressures of 2.09 $\mathrm{MPa}$ and $3.96 \mathrm{MPa}$, the calculated values of the Young's modulus did not range within the acceptable limits for this material and were excluded from Table 1. In addition, these values are not taken into account in the subsequent calculations and they do not appear in the respective diagrams.

\begin{tabular}{|c|c|c|c|c|c|c|c|c|}
\hline \multirow[b]{2}{*}{ Loops } & \multicolumn{4}{|c|}{ Uniaxial } & \multicolumn{4}{|c|}{ Triaxial confining pressure of $1.15 \mathrm{MPa}$} \\
\hline & $\begin{array}{l}\text { Deviator } \\
\text { stress } \\
(\mathrm{MPa})\end{array}$ & $\begin{array}{c}\text { Plastic } \\
\text { strain, } \varepsilon_{\mathrm{pl}} \\
\left(\mathrm{x} 10^{-3}\right)\end{array}$ & $\begin{array}{c}\text { Total } \\
\text { strain, } \varepsilon \\
\left(\times 10^{-3}\right)\end{array}$ & $\begin{array}{l}\text { Young's } \\
\text { modulus, } \\
\mathrm{E}(\mathrm{MPa})\end{array}$ & $\begin{array}{c}\text { Deviator } \\
\text { stress } \\
(\mathrm{MPa})\end{array}$ & $\begin{array}{c}\text { Plastic } \\
\text { strain, } \varepsilon_{\mathrm{pl}} \\
\left(\mathrm{x} 10^{-3}\right)\end{array}$ & $\begin{array}{c}\text { Total } \\
\text { strain, } \varepsilon \\
\left(\mathrm{x} 10^{-3}\right)\end{array}$ & $\begin{array}{l}\text { Young's } \\
\text { modulus, } \\
\text { E(MPa) }\end{array}$ \\
\hline $1^{\text {st }}$ & 1.85 & 0.447 & 0.672 & 7720 & 3.50 & 0.203 & 0.466 & 14105 \\
\hline $2^{\text {nd }}$ & 2.98 & 0.552 & 0.967 & 6720 & 4.64 & 0.332 & 0.702 & 12328 \\
\hline $3^{\text {rd }}$ & 4.67 & 0.845 & 1.591 & 6228 & 6.40 & 0.512 & 1.181 & 9426 \\
\hline $4^{\text {th }}$ & 5.78 & 1.319 & 2.314 & 5972 & 8.13 & 1.150 & 2.113 & 8374 \\
\hline $5^{\text {th }}$ & 7.04 & 2.244 & 3.525 & 5537 & - & - & - & - \\
\hline \multirow[b]{2}{*}{ Loops } & \multicolumn{4}{|c|}{ Triaxial confining pressure of $2.09 \mathrm{MPa}$} & \multicolumn{4}{|c|}{ Triaxial confining pressure of $3.96 \mathrm{MPa}$} \\
\hline & $\begin{array}{l}\text { Deviator } \\
\text { stress } \\
(\mathrm{MPa})\end{array}$ & $\begin{array}{c}\text { Plastic } \\
\text { strain, } \varepsilon_{\mathrm{pl}} \\
\left(\mathrm{x} 10^{-3}\right)\end{array}$ & $\begin{array}{l}\text { Total } \\
\text { strain, } \varepsilon \\
\left(x 10^{-3}\right)\end{array}$ & $\begin{array}{c}\text { Young's } \\
\text { modulus, } \\
\mathrm{E}(\mathrm{MPa})\end{array}$ & $\begin{array}{c}\text { Deviator } \\
\text { stress } \\
\text { (MPa) }\end{array}$ & $\begin{array}{c}\text { Plastic } \\
\text { strain, } \varepsilon_{\mathrm{pl}} \\
\left(\mathrm{x} 10^{-3}\right)\end{array}$ & $\begin{array}{l}\text { Total } \\
\text { strain, } \varepsilon \\
\left(x 10^{-3}\right)\end{array}$ & $\begin{array}{c}\text { Young's } \\
\text { modulus, } \\
\mathrm{E}(\mathrm{MPa})\end{array}$ \\
\hline $1^{\text {st }}$ & 3.09 & 0.912 & 0.946 & - & 2.26 & 1.041 & 1.041 & - \\
\hline $2^{\text {nd }}$ & 4.14 & 1.257 & 1.545 & - & 3.12 & 1.313 & 1.380 & - \\
\hline $3^{\text {rd }}$ & 5.35 & 1.960 & 2.549 & 9256 & 4.71 & 1.931 & 2.315 & 12343 \\
\hline $4^{\text {th }}$ & 6.36 & 3.164 & 3.957 & 8391 & 6.20 & 3.463 & 4.073 & 10091 \\
\hline \multirow[t]{2}{*}{$5^{\text {th }}$} & 7.87 & 6.594 & 7.665 & 7705 & 7.78 & 6.881 & 7.707 & 9531 \\
\hline & \multicolumn{4}{|c|}{ Triaxial confining pressure of $6.06 \mathrm{MPa}$} & & & & \\
\hline Loops & $\begin{array}{c}\text { Deviator } \\
\text { stress } \\
(\mathrm{MPa})\end{array}$ & $\begin{array}{c}\text { Plastic } \\
\text { strain, } \varepsilon_{\mathrm{pl}} \\
\left(\mathrm{x} 10^{-3}\right)\end{array}$ & $\begin{array}{c}\text { Total } \\
\text { strain, } \varepsilon \\
\left(\times 10^{-3}\right)\end{array}$ & $\begin{array}{l}\text { Young's } \\
\text { modulus, } \\
\mathrm{E}(\mathrm{MPa})\end{array}$ & & & & \\
\hline $1^{\text {st }}$ & 3.36 & 1.466 & 1.466 & - & & & & \\
\hline $2^{\text {nd }}$ & 5.19 & 1.929 & 2.216 & 18170 & & & & \\
\hline $3^{\text {rd }}$ & 6.25 & 3.349 & 3.810 & 13663 & & & & \\
\hline $4^{\text {th }}$ & 7.31 & 5.924 & 6.560 & 11601 & & & & \\
\hline $5^{\text {th }}$ & 8.94 & 10.458 & 11.247 & 11.358 & & & & \\
\hline
\end{tabular}

Table 1: Results of uniaxial and triaxial compressive tests under cyclic loading.

Fig.4a and Fig.4b show the relationship between the plastic strain and the elastic strain, respectively, as a function of the total strain of the mortar specimens subjected to both uniaxial and triaxial compressive cyclic loading for each of the five unloading-reloading loops. These diagrams show clearly the different behavior of the mortar specimens tested in uniaxial and triaxial cyclic loading. From a regression analysis, linear relationships between the plastic strain and total strain, as well as the elastic strain and total strain are derived, with a correlation coefficient higher than 0.95 , both in uniaxial (1) and triaxial (2) compressive cyclic loading scenarios.

It should be noted that the fitting of results for the triaxial cyclic compression tests took into account the data points from all three different confining pressures. 


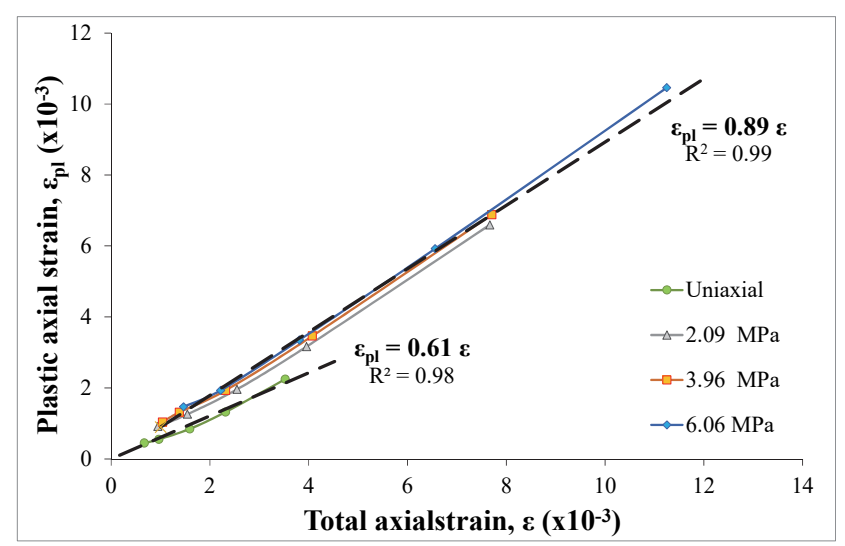

(a)

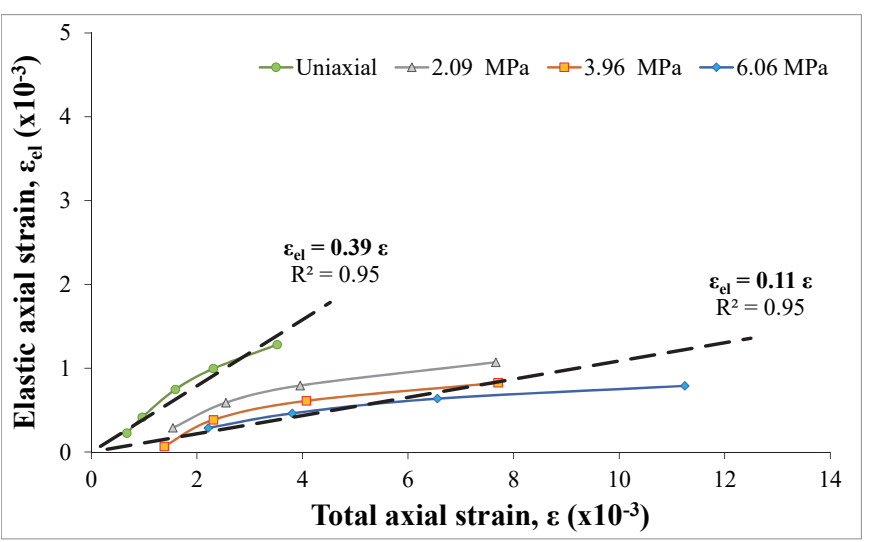

(b)

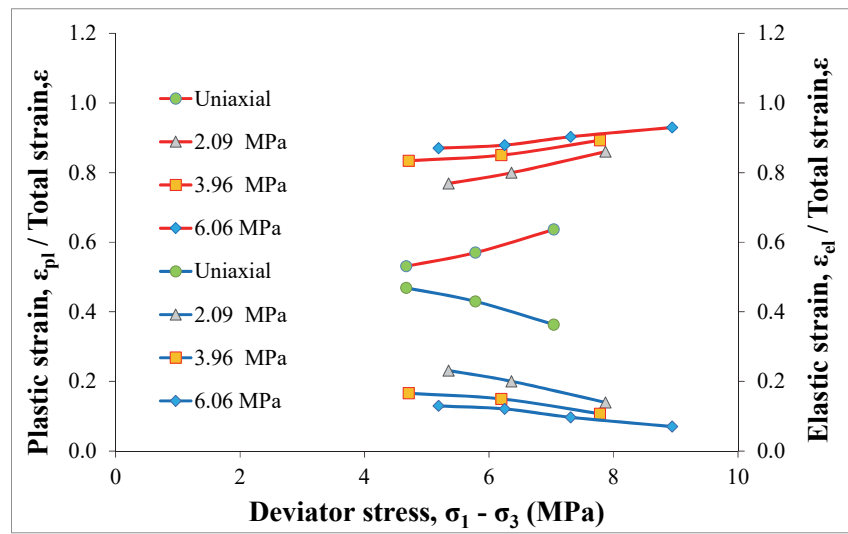

(c)

Figure 4: (a) Plastic strain vs. total strain; (b) Elastic strain vs. total strain; (c) $\varepsilon_{p l} / \varepsilon$ and $\varepsilon_{\varepsilon l} / \varepsilon$ ratios vs deviator stress.

For uniaxial compression cyclic test:

For triaxial compression cyclic test:

$$
\begin{aligned}
& \varepsilon_{p l}=0.61 \cdot \varepsilon, \quad \varepsilon_{e l}=0.39 \cdot \varepsilon \\
& \varepsilon_{p l}=0.89 \cdot \varepsilon, \quad \varepsilon_{e l}=0.11 \cdot \varepsilon
\end{aligned}
$$

The variation of the $\varepsilon_{p l} / \varepsilon$ and $\varepsilon_{e l} / \varepsilon$ ratios with the deviator stress is presented in Fig.4c for the last loops of the same experimental tests; the red lines correspond to the $\varepsilon_{p l} / \varepsilon$ ratio, while the blue lines correspond to the $\varepsilon_{e l} / \varepsilon$ atio. As expected, each pair of points corresponding to the same loop of the same test, satisfy Eq.(3).

$$
\frac{\varepsilon_{p l}}{\varepsilon}+\frac{\varepsilon_{e l}}{\varepsilon}=1
$$

Fig. 5 a presents the relationship between the plastic strain and the deviator stress for the uniaxial and the triaxial cyclic compression test under confining pressures of 2.09 $\mathrm{MPa}, 3.96 \mathrm{MPa}$ and $6.06 \mathrm{MPa}$. This diagram confirms the different behavior of the mortar specimens tested in uniaxial and triaxial cyclic loading. Using regression analysis, exponential

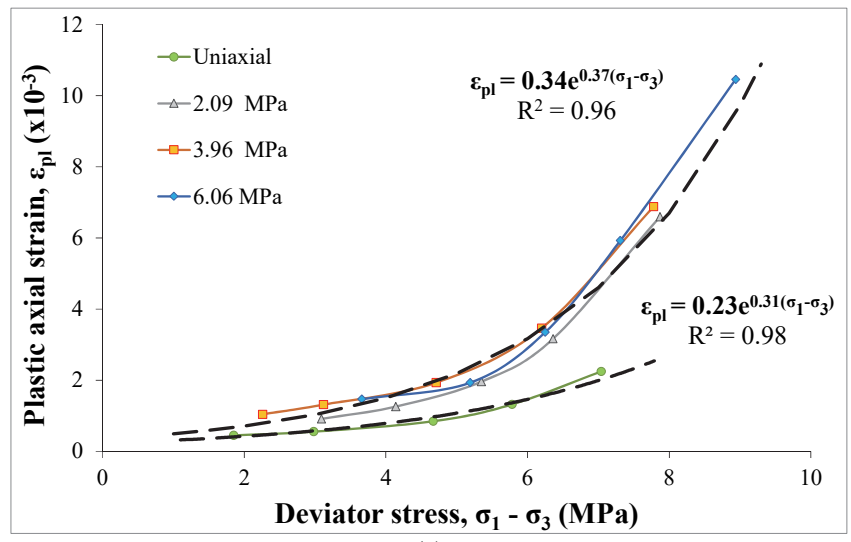

(a)

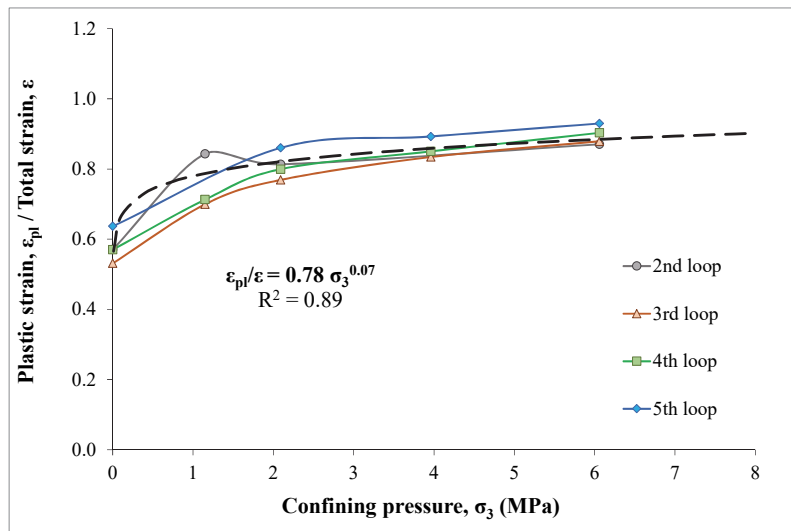

(b)

Figure 5: (a) Plastic strain vs. deviator stress; (b) $\varepsilon_{p l} / \varepsilon$ vs. confining pressure. 
relationships between the plastic strain and deviator stress are derived, with a correlation coefficient higher than 0.96 , for uniaxial compression (4) and triaxial compression (5) cyclic tests. The exponential relationships in Fig.5a are not applicable near the zero deviator stress values, since there are no plastic strains at this loading condition.

For uniaxial compression cyclic test:

For triaxial compression cyclic test:

$$
\begin{aligned}
& \varepsilon_{p l}=0.23 \cdot e^{0.31\left(\sigma_{1}-\sigma_{3}\right)} \\
& \varepsilon_{p l}=0.34 \cdot e^{0.37\left(\sigma_{1}-\sigma_{3}\right)}
\end{aligned}
$$

The effect of the confining pressure $\sigma_{3}$ of the triaxial compression cyclic tests on the $\varepsilon_{p l} / \varepsilon$ ratio is presented in Fig. $5 \mathrm{~b}$. The fitting results for the triaxial cyclic compression tests were derived by including all of the data points from the four last loops. Using regression analysis, a power relationship between the $\varepsilon_{p l} / \varepsilon$ ratio and the confining pressure is derived with a correlation coefficient equal to 0.89 , as expressed by Eq.(6).

$$
\frac{\varepsilon_{p l}}{\varepsilon}=0.78 \cdot \sigma_{3}^{0.07}
$$

\section{Young's modulus degradation}

The degradation of Young's modulus is a crucial parameter that reflects the damage of the pozzolanic lime mortar under compressive loads. In the present study, the slope of the line replacing the loop which is formed by the unloading and reloading curve is defined as the elastic modulus $E_{d}$ (Fig.2). The Young's modulus of every cycle, determined from the cyclic uniaxial and triaxial compressive tests is listed in Table 1. In order to avoid possible errors caused by low stress levels, the Young's modulus values of the first cycles in some of the triaxial compression tests are ignored.

The variation of the calculated Young's modulus with the confining pressure for each loop is presented in Fig.6a. The increasing trend of the elastic modulus as a function of the confining pressure is evident. Fig.6b shows the Young's modulus variation with the total strain for all of the mortar specimens tested in both uniaxial and triaxial compression tests under different confining pressures. The results indicate that the Young's modulus decreases with increasing total strain, which may be due to the propagation of initial defects, which were amplified upon increased load and successive loading cycles. This degradation behavior is related to weak patterns of damage, such as microvoids and microcracks, which are not able to modify and influence the elastic modulus of the specimen.

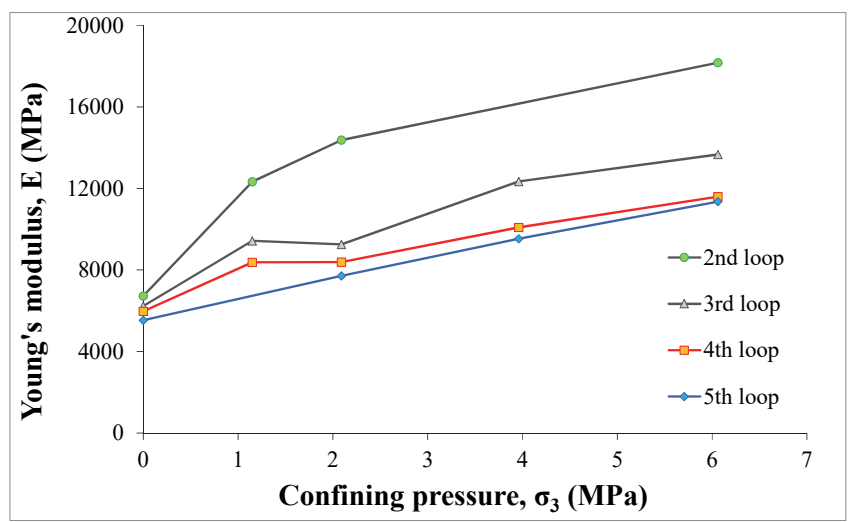

(a)

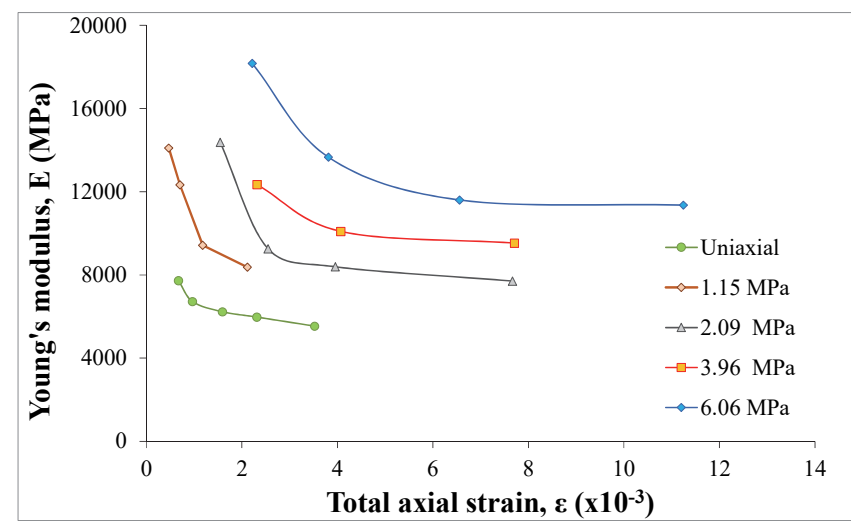

(b)

Figure 6: The variation of Young's modulus with (a) the confining pressure and (b) the total strain for mortar specimens tested in uniaxial and triaxial cyclic loading under different confining pressures.

\section{Failure mode}

As previously discussed, the failure mode of the pozzolanic lime mortar specimens subjected to uniaxial and triaxial cyclic compressive loading is directly related to the type of stress-strain behavior (i.e., strain-softening vs. strain-hardening) as well as to the stress level of the confining pressure in triaxial compression tests. In the case of uniaxial compression cyclic tests and triaxial compression cyclic test at low confining pressure (1.15 MPa) (Fig.3a), the mortar exhibits a strain-softening behavior. Two different failure modes were observed during the uniaxial compressive loading of mortar. Some specimens failed along a single shear plane (Fig.7a) and others failed in axial splitting (Fig.7b). The specimen subjected to triaxial compression cyclic test with confining pressure of $1.15 \mathrm{MPa}$ failed along a single shear plane (Fig.7c).

As previously stated, the mortar specimens subjected to triaxial compressive cyclic loading at higher $(2.09-6.06 \mathrm{MPa})$ confining pressures exhibited a strain-hardening behavior (Fig.3a). In this case, the failure mode is characterized by large axial strain up to the maximum compressive stress and large lateral expansion of the cylindrical specimen. A con- 
jugate shear plane failure with lateral expansion is presented in Fig.8a for the case of triaxial compression test with confining pressure of $2.09 \mathrm{MPa}$. In the case of the $3.96 \mathrm{MPa}$ confining pressure, conjugate shear planes are observed (Fig.8b), combined with a remarkable lateral expansion and some trace of Lüders lines [23].

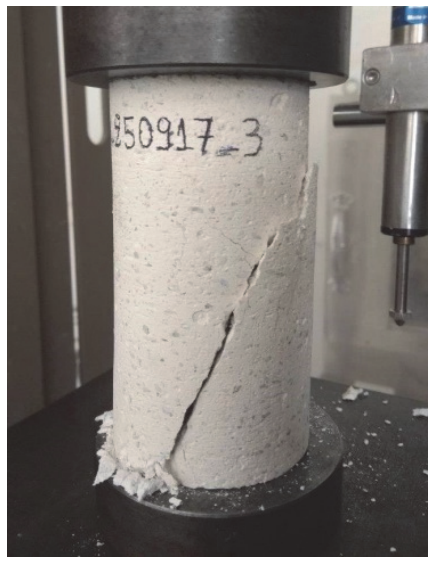

(a)

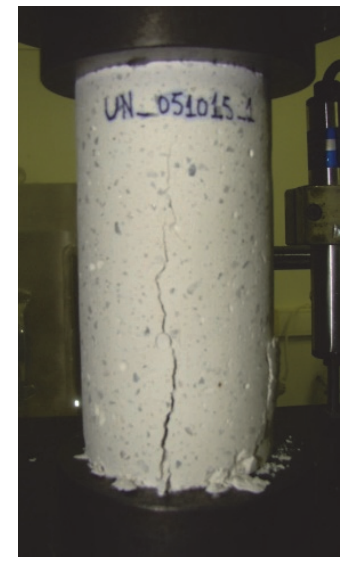

(b)

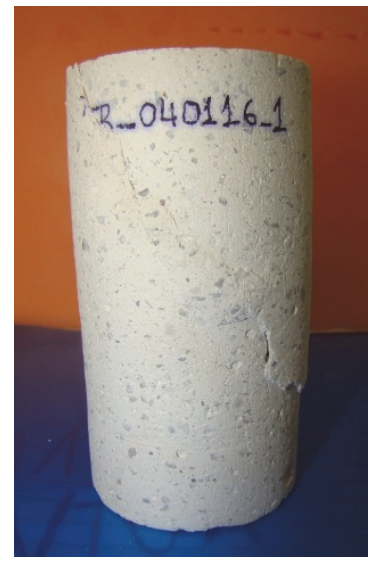

(c)

Figure 7: Typical crack patterns in pozzolanic lime mortar cylindrical specimens. (a) Shear plane failure in uniaxial compression test; (b) Axial splitting failure in uniaxial compression test; (c) Single shear plane failure in triaxial compression test with confining pressure of $1.15 \mathrm{MPa}$.

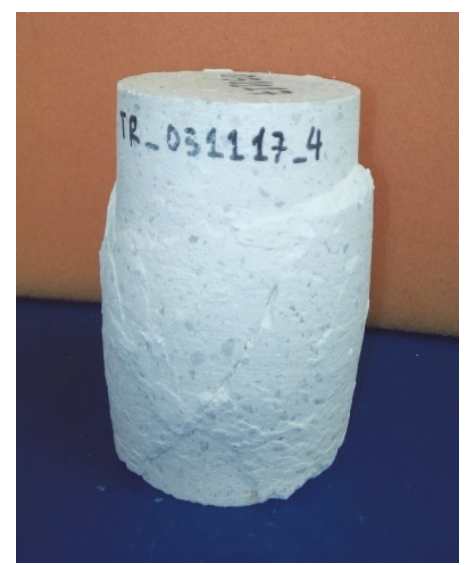

(a)

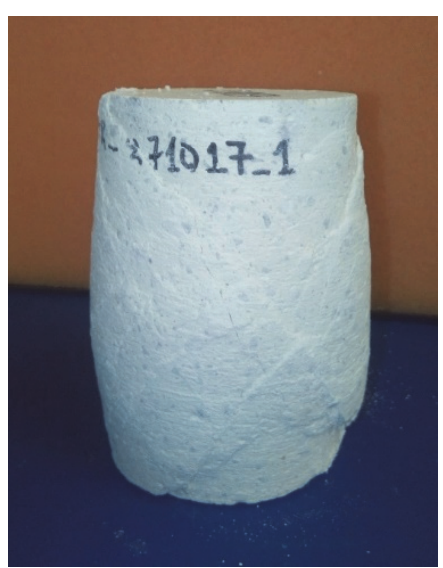

(b)

Figure 8: Typical crack patterns in pozzolanic lime mortar cylindrical specimens under triaxial loading. (a) Failure on conjugate shear planes for a confining pressure of $2.09 \mathrm{MPa}$; (b) Failure on conjugate shear planes for a confining pressure of $3.96 \mathrm{MPa}$.

\section{Simplified damage evolution relationship for cyclic tests under triaxial compression}

The pozzolanic lime mortar uniaxial and triaxial compression cyclic tests exhibit Young's modulus degradation caused by progressive damage accumulation. As mentioned before, Fig.6b confirms this degradation process and can be utilized to characterize the damage evolution relationship. The damage part can be implemented by a damage index, $d$, which is equal to zero in the absence of damage and equal to one in the case of complete damage. Under uniaxial and triaxial loading conditions, the calculated "damaged" elastic modulus, $E_{d}$ is related to the initial "undamaged" elastic modulus $E_{o}$, according to the following equation:

$$
E_{d}=(1-d) \cdot E_{0}
$$

The values of damaged Young's modulus $E_{d}$ were calculated graphically from each loop of the triaxial compressive cyclic loading (Table 1). It is important to note that in this study as initial undamaged elastic modulus $E_{o}$ was assumed to be the modulus that was calculated using the second or third loop for each confining pressure of the triaxial compression tests. The corresponding values of the damage index were calculated by rearranging relationship (7):

$$
d=1-\frac{E_{d}}{E_{0}}
$$

Fig.9a illustrates the calculated values for the damage index using Eq.(8), for the triaxial compression cyclic tests with confining pressures of 2.09 $\mathrm{MPa}, 3.96 \mathrm{MPa}$, and 6.06 MPa. Note, that the values obtained for the series of triaxial tests 
with a lateral pressure of $1.15 \mathrm{MPa}$ were not used in Fig.9a and in the subsequent derivation of the damage index relationship because of two reasons: (a) these tests exhibited a strain-softening behavior, while specimens under higher triaxial compression pressures exhibited a strain-hardening behavior and (b) the behavior of the specimen tested under a lateral pressure of $1.15 \mathrm{MPa}$ exhibited a failure mode (Fig.7c) similar to that of uniaxial test (Fig.7a) and dissimilar to that of high pressure triaxial tests (Fig.8).

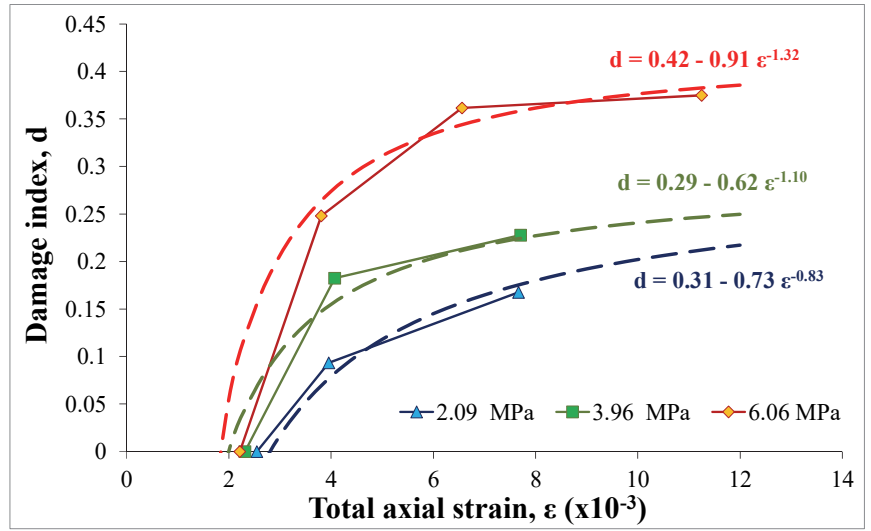

(a)

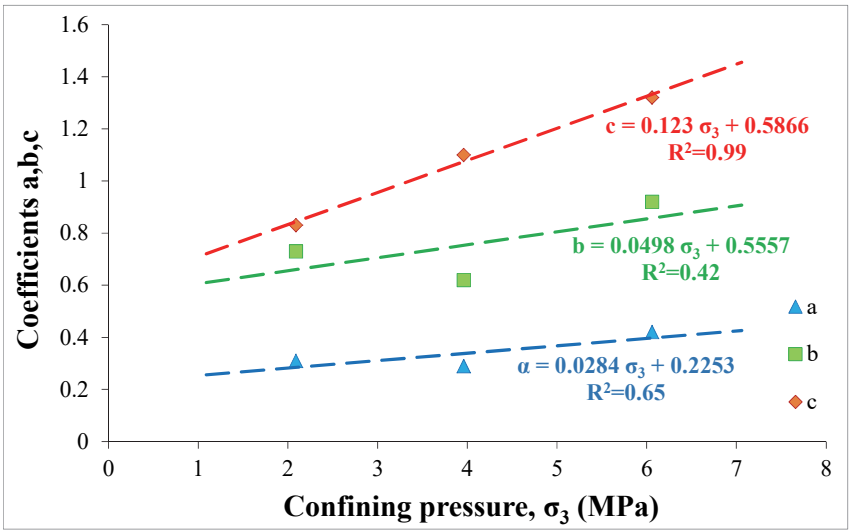

(b)

Figure 9: (a) Fitting results of damage index $d$ for triaxial compression cyclic tests with confining pressures of $2.09 \mathrm{MPa}, 3.96 \mathrm{MPa}$ and $6.06 \mathrm{MPa}$. (b) Fitting results for coefficients $a, b$ and $c$.

In this work, a similar model with those proposed for concrete [24, 25, 26, 27, 28, 29] was adopted in order to predict the damage evolution relationship for the pozzolanic lime mortar, which is described in Eq.(9):

$$
d=a-b \cdot \varepsilon^{-c}
$$

where $a, b$ are coefficients of the damage evolution relationship; $c$ is an optimum order related to the speed of damage propagation, which controls the curvature of the damage evolution curve.

The fitting curves on the calculated damage index for each confining pressure are plotted in Fig.9a, while the fitting results for coefficients $a, b$ and $c$ are listed in Table 2 .

\begin{tabular}{cccc}
\hline$\sigma_{3}$ & $a$ & $b$ & $c$ \\
2.09 & 0.31 & 0.73 & 0.83 \\
3.96 & 0.29 & 0.62 & 1.10 \\
6.06 & 0.42 & 0.91 & 1.32 \\
\hline
\end{tabular}

Table 2: Fitting results for coefficients $a, b$ and $c$.

As illustrated in Fig.9b, the coefficients a, b and $\mathrm{c}$ are functions of the confining pressure. From a regression analysis, these coefficients are determined in Eqs.(10-12). The corresponding fitting lines and least square correlation coefficients are shown in Fig.9b.

$$
\begin{aligned}
& a=0.0284 \cdot \sigma_{3}+0.2253 \\
& b=0.0498 \cdot \sigma_{3}+0.5557 \\
& c=0.123 \cdot \sigma_{3}+0.5866
\end{aligned}
$$

The evolution of $d$ as a function of the confining pressure (Eq.(13)) is calculated by substituting Eqs.(10-12) in Eq.(9):

$$
d=0.0284 \cdot \sigma_{3}+0.2253-\left(0.0498 \cdot \sigma_{3}+0.5557\right) \cdot \varepsilon^{-\left(0.123 \cdot \sigma_{3}+0.5866\right)}
$$

The verification of this damage model expressed in Eq.(13) is shown in Fig.10, where the predicted elastic moduli $E_{d}$ for each loop of the triaxial compression cyclic tests with confining pressure of $2.09 \mathrm{MPa}$ (Fig.10a) and 6.06 MPa (Fig. $10 \mathrm{~b})$ are compared with the corresponding experimental values. The values of the predicted elastic moduli are in good agreement with the elastic moduli that were determined experimentally. The different behavior between uniaxial and triaxial compression tests with respect to plastic strain versus total strain and plastic strain versus deviator stress can be 
attributed to the completely different stress fields that are developed in each test, as a result of the application of lateral pressure in the triaxial compression tests. Note that the proposed damage evolution equation applies only to the prepeak region. As presented experimentally $[16,17]$, the degradation of the elastic modulus becomes more pronounced in the post-peak region and to the specific mortar design. Therefore, additional experimental work should be carried out in the future in order to investigate whether the Young's modulus degradation process can be utilized to lead to a complete damage evolution law.

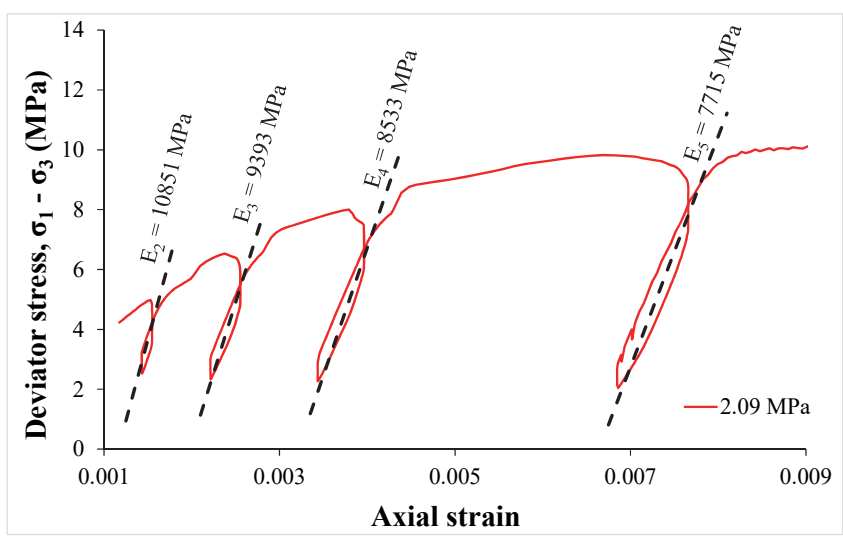

(a)

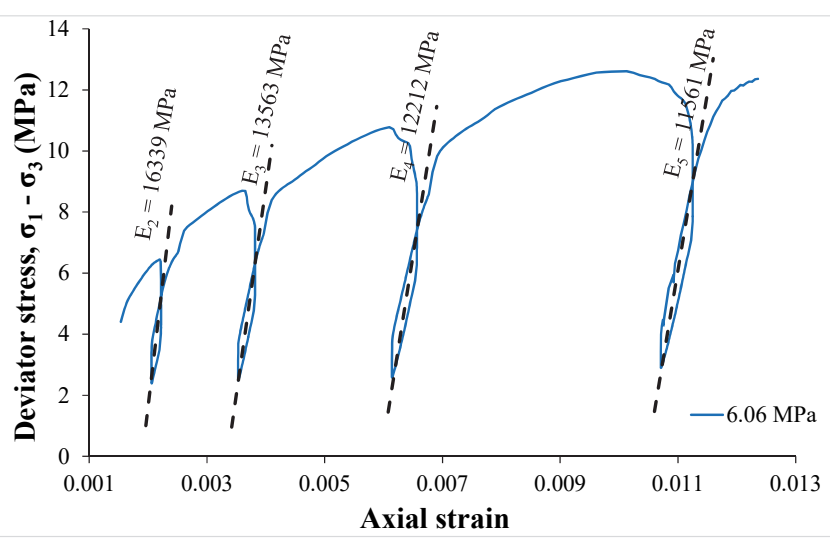

(b)

Figure 10: Comparison of experimental results and the proposed model for damage evolution on triaxial compression cyclic tests with (a) $2.09 \mathrm{MPa}$ and (b) $6.06 \mathrm{MPa}$ confining pressure.

\section{CONCLUSIONS}

I $\mathrm{n}$ the present study, uniaxial and triaxial compression tests under unloading-reloading (cyclic loading) conditions were conducted to elucidate the stress-strain and the material deformation behavior, as well as to derive a damage evolution relationship in the pre-peak region of a pozzolanic lime mortar.

Linear equations can be used to describe the relationship between the plastic strain and total strain, while exponential equations can be utilized to correlate the plastic strain and deviator stress in the case of both uniaxial and triaxial compression cyclic tests. The ratio $\varepsilon_{p} / \varepsilon$ is very high (0.89) for the triaxial compression tests, while it becomes lower (0.61) for uniaxial compression. In addition, a power relationship was derived between the $\varepsilon_{p} l / \varepsilon$ and the confining pressure $\sigma_{3}$. A strain-softening behavior can be used to describe the uniaxial test and the triaxial compression test at low confining pressure $(1.15 \mathrm{MPa})$. Triaxial compression tests at higher confining pressures can be described by a strain-hardening behavior. These different types of deformations are also reflected in the macroscopic failure mode of the pozzolanic lime mortar specimens subjected to uniaxial and triaxial cyclic compressive loading. The macroscopic crack pattern of mortar specimens under uniaxial compression are mainly shear failure and, in some cases, split failure, while the specimen subjected to triaxial compression cyclic test with relatively low confining pressure (1.15 MPa) failed along a single shear plane. Under triaxial compression tests with higher confining pressures, failure occurs along a single shear plane or conjugate shear planes combined with lateral expansion.

Given that the Young's modulus is related to stress, strain and the susceptibility to crack initiation, propagation and coalescence, the quantification of changes in the elastic modulus can be used to describe the effects of cyclic loading on material deformation. The observed decrease of Young's modulus with increasing strain is attributed to the propagation of initial defects and microfractures in these mortar specimens.

Increasing the confining pressure in triaxial compression tests affects the degradation of the elastic modulus which can be expressed using a damage index. A mathematical expression is proposed which can calculate the damage index as a function of the confining stress for the case of pozzolanic lime mortars under triaxial compressive cyclic loading. This expression was derived based on a specific pozzolanic mortar design but can be easily expanded to similar mortar designs. The predicted elastic moduli for different unloading-reloading loops are in good agreement with the experimental values. As the damage evolution relationship quantifies changes in the elastic modulus of the material as a function of the confining stress, a full characterization of the pre-peak behavior of the material under different loading scenarios can be obtained. This information can be fully exploited when modeling the behavior of these mortars for a specific application.

\section{ACKNOWLEDGEMENTS}

This research was co-financed by the European Union (European Social Fund-ESF) and Greek national funds through the Operational Program "Education and Lifelong Learning" of the National Strategic Reference Framework 
(NSRF) - Research Funding Program: THALES: Reinforcement of the interdisciplinary and/or inter-institutional research and innovation.

\section{REFERENCES}

[1] Kaklis, K.N., Mavrigiannakis, S.P., Agioutantis, Z.G. and Maravelaki-Kalaitzaki, P. (2018). Characterization of pozzolanic lime mortars used as filling material in shaped grooves for restoring member connections in ancient monuments, International Journal of Architectural Heritage, 12(1), pp. 75-90.

DOI: 10.1080/15583058.2017. 1377313.

[2] Veiga, R.M., Velosa, A. and Magalhaes, A. (2009). Experimental applications of mortars with pozzolanic additions: characterization and performance evaluation, Construction and Building Materials, 23, pp. 318-327.

DOI: 10. 1016/j.conbuildmat.2007.12.003.

[3] Aggelakopoulou, E., Bakolas, A. and Moropoulou, A. (2011). Properties of lime-metakaolin mortars for the restoration of historic masonries, Applied Clay Science, 53(1), pp. 15-19. DOI: 10.1016/j.clay.2011.04.005.

[4] Kourkoulis, S.K., Pasiou, E.D., Triantis, D., Stavrakas and I., Hloupis, G. (2015). Innovative experimental techniques in the service of restoration of stone monuments - Part I: the experimental set up, Procedia Engineering, 109, pp. 268-275. DOI: 10.1016/j.proeng.2015.06.232.

[5] Kourkoulis, S.K. and Pasiou, E.D. (2015). Interconnected epistyles of marble monuments under axial loads, International Journal of Architectural Heritage, 9(3), pp. 177-194. DOI: 10.1080/15583058.2012.756079.

[6] Benin, A.V., Semenov, A.S., Semenov, S.G., Beliaev, M.O. and Modestov, V.S. (2017). Methods of identification of concrete elastic-plastic-damage models, Magazine of Civil Engineering, 8, pp. 279-297.

DOI: 10.18720/MCE. 76.24.

[7] Gatelier, N., Pellet, F., Loret, B. (2002). Mechanical damage of an anisotropic porous rock in cyclic triaxial tests, International Journal of Rock Mechanics and Mining Sciences, 39(3), pp. 335-354.

DOI: 10.1016/S1365-1609 (02)00029-1.

[8] Jia, C., Xu, W., Wang, R., Wang, W., Zhang, J. and Yu, J. (2018). Characterization of the deformation behavior of fine-grained sandstone by triaxial cyclic loading, Construction and Building Materials, 162, pp. 113-123.

DOI: 10. 1016/j.conbuildmat.2017.12.001.

[9] Neuenschwander, M., Knobloch, M. and Fontana, M. (2016). Suitability of the damage-plasticity modelling concept for concrete at elevated temperatures: Experimental validation with uniaxial cyclic compression tests, Cement and Concrete Research, 79, pp. 57-75. DOI: 10.1016/j.cemconres.2015.07.013

[10] Li, B., Xu, L., Chi, Y., Huang, B. and Li, C. (2017). Experimental investigation on the stress-strain behavior of steel fiber reinforced concrete subjected to uniaxial cyclic compression, Construction and Building Materials, 140, pp. 109-118. DOI: 10.1016/j.conbuildmat.2017.02.094.

[11] Kaklis, K., Agioutantis, Z., Mavrigiannakis, S. and Maravelaki-Kalaitzaki, P. (2018). On the experimental investigation of pozzolanic lime mortar stress-strain behavior and deformation characteristics when subjected to unloading-reloading cycles, Procedia Structural Integrity, 10, pp. 129-134. DOI: 10.1016/j.prostr.2018.09.019.

[12] Costigan, A. and Pavia, S. (2010). Influence of mechanical properties of lime mortar on the strength of masonry, $2^{\text {nd }}$ Conference on Historic Mortars - HMC 2010 and RILEM TC 203-RHM final workshop, Editor(s): J. Valek, C. Groot and J.J. Hughes, e-ISBN: 978-2-35158-112-4, Publisher: RILEM Publications SARL, pp. 457-466.

[13] Gameiro, A., Santos Silva, A., Faria, P., Grilo, J., Branco, T., Veiga, R. and Velosa, A. (2014). Physical and chemical assessment of lime-metakaolin mortars: Influence of binder: aggregate ratio, Cement and Concrete Composites, 45, pp. 264-271. DOI: 10.1016/j.cemconcomp.2013.06.010.

[14] Bieniawski, Z.T. and Bernede, M.J. (1979). Suggested methods for determining the uniaxial compressive strength and deformability of rock materials, International Journal of Rock Mechanics and Mining Sciences \& Geomechanics Abstracts, 16(5), pp. 135-140. DOI: 10.1016/0148-9062(79)90262-6.

[15] Vogler, U.W. and Kovari, K. (1978). Suggested methods for determining the strength of rock materials in triaxial compression, International Journal of Rock Mechanics and Mining Sciences \& Geomechanics Abstracts, 15(2), pp. 47-51. DOI: 10.1016/0148-9062(78)91677-7.

[16] Mogi, K. (2007). Experimental rock mechanics, Geomechanics Research Series 3, Balkema proceedings and monographs in engineering, water and earth sciences, The Netherlands, Taylor \& Francis/Balkema.

[17] Bahn, B.Y. and Hsu, C.T.T. (1998). Stress-strain behavior of concrete under cyclic loading, ACI Materials Journal, 95(2), pp. 178-193.

[18] Chen, W.F. and Han, D.J. (1988). Plasticity for structural engineers, New York, Springer-Verlag.

[19] Li, B., Xu, L., Chi, Y., Huang, B. and Li, C. (2017). Experimental investigation on the stress-strain behavior of steel fiber reinforced concrete subjected to uniaxial cyclic compression, Construction and Building Materials, 140, pp. 109-118. DOI: 10.1016/j.conbuildmat.2017.02.094. 
[20] Sima, J.F., Roca, P. and Molins, C. (2008). Cyclic constitutive model for concrete, Engineering Structures, 30(3), pp. 695-706. DOI: 10.1016/j.engstruct.2007.05.005.

[21] Lam, L. and Teng, J.G. (2009). Stress-strain model for FRP-confined concrete under cyclic axial compression, Engineering Structures, 31(2), pp. 308-321. DOI: 10.1016/j.engstruct.2008.08.014.

[22] Farmer, I. (1982). Engineering behaviour of rocks. Second edition, New York, Chapman and Hall.

[23] Olsson W.A. (2000). Origin of Lüders' bands in deformed rock, Journal of Geophysical Research Atmospheres, 105(B3), pp. 5931-5938. DOI: 10.1029/1999JB900428.

[24] Osorio, E., Bairán, J.M. and Marí, A.R. (2013). Lateral behavior of concrete under uniaxial compressive cyclic loading, Materials and Structures, 46(5), pp. 709-724. DOI: 10.1617/s11527-012-9928-9.

[25] Sinaie, S., Heidarpour, A., Zhao, X.L. and Sanjayan, J.G. (2015). Effect of size on the response of cylindrical concrete samples under cyclic loading, Construction and Building Materials, 84, pp. 399-408. DOI: 10.1016 / j.conbuildmat. 2015.03.076.

[26] Breccolotti, M., Bonfigli, M.F., D’Alessandro, A. and Materazzi, A.L. (2015). Constitutive modeling of plain concrete subjected to cyclic uniaxial compressive loading, Construction and Building Materials, 94, pp. 172-180. DOI: $10.1016 /$ j.conbuildmat.2015.06.067.

[27] He, W., Wu, Y.F. and Liew, K.M. (2008). A fracture energy based constitutive model for the analysis of reinforced concrete structures under cyclic loading, Computer Methods in Applied Mechanics and Engineering, 197(51-52), pp. 4745-4762. DOI: 10.1016/j.cma.2008.06.017.

[28] Yu, T., Zhang, B. and Teng, J.G. (2015). Unified cyclic stress-strain model for normal and high strength concrete confined with FRP, Engineering Structures, 102, pp. 189-201. DOI: 10.1016/j.engstruct.2015.08.014.

[29] Hafezolghorani, M., Hejazi, F., Vaghei, R., Jaafar, M.S.B. and Karimzade K. (2017). Simplified Damage Plasticity Model for Concrete, Structural Engineering International, 27(1), pp. 68-78. DOI: 10.2749/101686616X1081. 